\title{
THE CONCEPT OF COOPERATIVE AUTOMATION IN CARS: RESULTS FROM THE EXPERIMENT “OVERTAKING ON HIGHWAYS”
}

\author{
Lars Biester \\ Robert Bosch GmbH \\ Stuttgart, Germany \\ E-mail: lars.biester@de.bosch.com
}

\begin{abstract}
Summary: As the interaction between human and machine continues to change, due to the increase of system functionalities, a concept of human-car cooperation covering the effects of this change has been developed. Proceeding from this concept, an initial analysis of the actual human-car interaction including the wishes of today's drivers will be the main subject of this paper. An experimental design, based on the concept of cooperation and preliminary studies, was developed. First results on the quality of cooperation, situational awareness and trust indicate the concept's profound adaptableness to future human-car interactions.
\end{abstract}

\section{INTRODUCTION}

The interaction between human and machine will change fundamentally within the next decades since the technological sophistication and complexity of systems in the intelligent transportation sector is increasing profoundly. Concentrating on the automobile sector, automation like semiautonomous driving or car-to-car communication is technically well developed, so that a launch is conceivable. With consideration of drivers, the possibilities and necessities to design those interactions will become even more important than they are today. Furthermore, one of the major questions to be answered is: How do drivers react to these new technologies? In this cohesion, a summarizing synoptic approach covering the relevant aspects of the specific humanmachine context has to be seen as mandatory.

\section{THE BASIC CONCEPT: COOPERATIVE AUTOMATION IN CARS}

Sheridan (1992) has already described the possibility of a so-called cooperative control, where action is initiated by one of the actors, human or machine, to which the other adapts himself or refines the action.

Picking up this idea and integrating other existing approaches in the HMI-Sector under the aspect of cooperation and collaboration, the concept of cooperation between humans and cars (Biester, 2004) was developed to create a platform for the interaction as a whole.

\section{Definition}

Cooperation will be defined here as a general exchange process between a minimum of two actors, which are, in relation to the overall task, dependent on each other. Both partners take dynamical charge of parts of the overall task in order to reach a solution, a positive result of the task or to satisfy a social need (e.g., effect-/cost efficiency and security). Additionally, it is implicated that this teamwork shall benefit for both sides. 


\section{Indicators of the benefit through cooperation}

The benefit of this approach is, keeping the specific basic conditions in mind (Herczeg, 2002), that theoretically testable indicators were deduced, with which an analysis of the concept of cooperation in human-car interaction and the proclaimed positive result in comparison to other approaches is possible:

- Optimization of the exchange processes between human and car

- Promotion of situational awareness (interference)

- Increase of the interaction quality

- Assistance and enhancement of the communication

- Amount of questions, kind of the questions (style)

- Length of the questions etc., gesture, mimics

- Optimization of stress and strain

- objective workload (heart rate, EDA etc.)

- subjective workload (questionnaires etc.)

- Building up know-how

- Transparency of system states

- Increase of acceptance (trust etc.)

- Satisfaction

The essential supremacy of cooperation is the synergy that can be most plainly shown when the combined action of the two actors yields a net benefit that is bigger than the attainable benefit of each actor without cooperation.

\section{METHODOLOGICAL APPROACH FOR VERIFYING THE CONCEPT}

The previously introduced indicators shall be examined in a series of experiments with regard to their practical relevance and their presumed synergetic effects.

The main task was to find an experimental scenario that allows on one hand the assessment of the developed concept and on the other hand the possible experience of the concept of cooperation by a user in a driving simulator.

Prior to further considerations, an online questionnaire $(\mathrm{N}=509)$ was conducted in order to understand the current preferences and desires of drivers and to deduce the experimental scenario. This was conducted for 66 primary, secondary and tertiary functions respective driving tasks in automobiles (the limitation to 66 functions was a result of an expert workshop). Figure 2 shows the means of 22 exemplary selected functions, with possible answers ranging from 1 (manually) to 7 (full automation). 


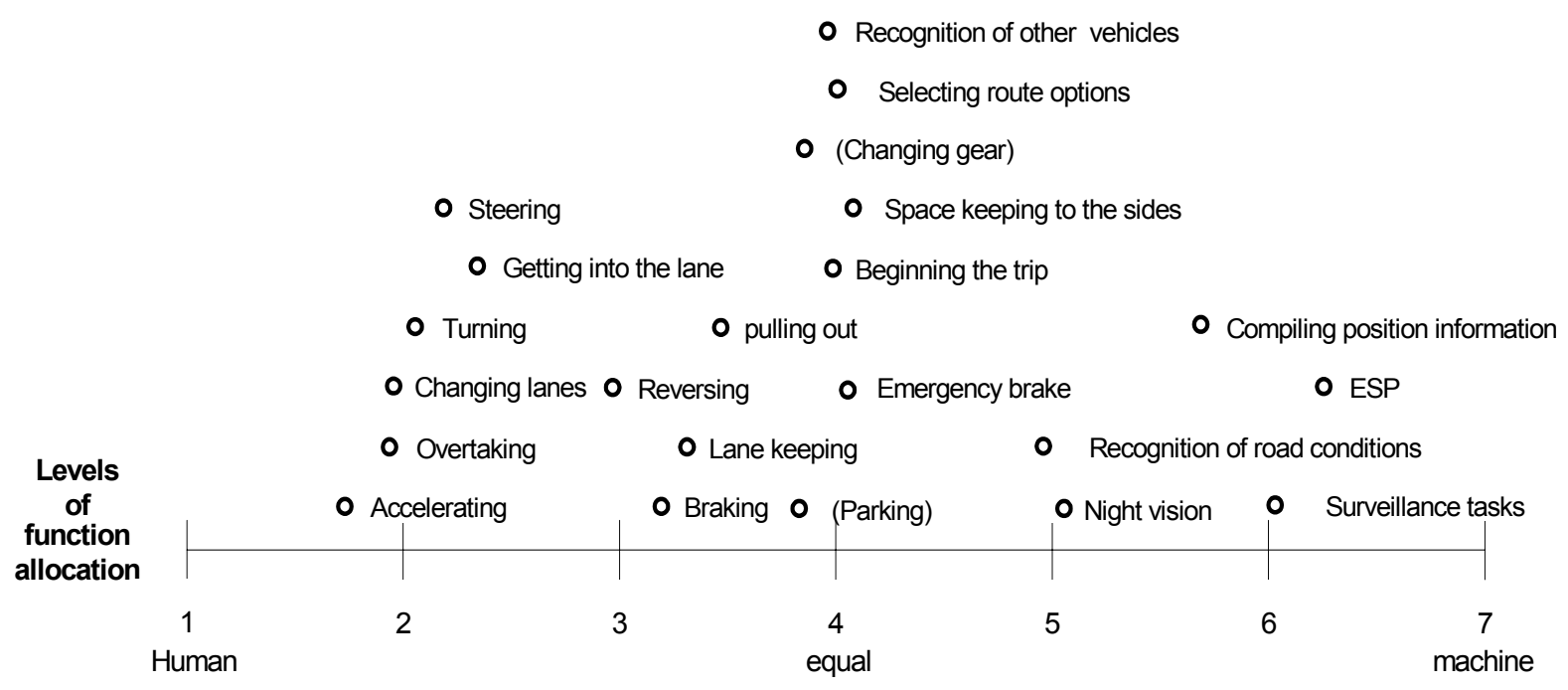

\section{Figure 1. Means of the desired function allocation of 22 exemplary functions in cars (values in parentheses do have a standard deviation $>2$ )}

Especially the range of answers between 3 and 5, where both machine and human would have equal rights, will have a high potential for the cooperative coverage with the associated driving task.

The results indicated that the interviewed persons wished to carry out direct manipulative functions like steering and speeding up on their own. On the contrary, drivers would delegate functions to the respective systems (e. g., to avert skidding) that are more likely conducted safely and reliable by mechanical automation.

From this perspective especially "overtaking" suits implementation of cooperative automation: first, because this driving situation combines several of the direct manipulative functions that drivers would like to undertake themselves (see Figure 1) and second, this maneuver corresponds with many upcoming systems like Blind Spot Detection (BSD) or systems for circumferential visibility. Additionally, the importance of an investigation of an "overtaking" driving situation becomes evident because of the problems of older road users with such difficult maneuvers, as results like those from the EU-project AGILE emphasize (Panou, Bekiaris, \& Palma, 2003).

\section{EXPERIMENTAL DESIGN}

Overall, in order to test the questions deduced from the concept, a driving task with a high potential regarding the cooperation-based interaction had to be chosen.

\section{The experimental setting}

In the first driving simulator experiment, the driver had to perform several standardized overtaking maneuvers on a two-lane German highway either manually, cooperatively, half automatic or automatic in a between-subject design. The setting consisted of four segments of driving, 15 minutes each, in which 12 trucks had to be overtaken either in bends or on straight lanes. 


\section{Subjects}

The subjects were from 25 to 40 years old with a range of 10,000 to 20,000 kilometers driving experience per year.

Beside these control variables, variables such as control conviction and cooperative behavior in their working environment were collected.

\section{Independent variables}

Manual System. The participants had to drive on the highway scenario manually, without any system to interact with.

Cooperative System. The subjects in this group were interacting with a Wizard of Oz-system. The Wizard of Oz testing is an experimental user interface evaluation method in which the user of the system is made to believe that he or she is interacting with a fully implemented system, though all or part of the interaction of the system is controlled by a human, a wizard, or several of them. A dialog concept was developed on the basis of the Cooperative Principle (Grice, 1975) and six functions like Lane Change Aid (LCA) were implemented.

Half automatic System. The participants in this group could press a button on a touch screen if they wanted assistance from the system. After pressing the button, the system took over automatically.

Automatic System. The system that the participants in this group experienced acted fully automatic. The subjects were asked to supervise the actions.

\section{Dependent variables}

During the experiment regarding the mentioned indicators, bio-physiological parameters including ECG and GSR were measured, as well as 40 driving parameters like speed and lane keeping. Additionally, questionnaires on situational awareness, workload, acceptance of the system and trust in the system had to be completed in between the segments. Afterwards, in addition to the mentioned questionnaires, questions on simulator sickness (Kennedy \& Lane, 1993), the quality of cooperation (Skjerve \& Skraaning, 2004), the communication with the system and the expected influence of such a system on the drivers capabilities were asked.

\section{RESULTS}

As this experiment has a wide range of results on subjective and objective bases, only some shall be presented here.

\section{Quality of cooperation}

Human-car cooperation implies coordination and thus communication with a purpose, and to be efficient, the exchanges between human and car should have a mutually manifest purpose (i.e., the achievement of the operational goal). For this reason, the Cooperative Principle (Grice, 1975) 
and its associated maxims seem to serve as an adequate framework for assessments of the quality of human-car cooperation. Therefore, the participants of the cooperative system group were asked six questions regarding the dialog concept (Skjerve \& Skraaning, 2004):

1. To what extent did the system provide relevant information about its activities?

2. To what extent did you receive relevant information from the system on time to benefit from it?

3. To what extent did you immediately understand the information that the system provided?

4. To what extend did the automatic system perform the activities you requested of it (e.g., answer questions?

5. To what extend did the system perform the activities you expected it to do?

6. Overall, how would you characterize the cooperation between you and the system?

This Halden Human-Automation Cooperation Questionnaire demonstrated a high inter-item reliability in this experiment as the Cronbach's alpha coefficient was 0.81 .

Table 1. Mean, range and standard deviation for the six items of the Halden Co-operation Scale in the cooperative system group

\begin{tabular}{ccccc}
\hline Item No. & Valid N & Mean & Standard deviation & Range \\
\hline Item 1 & 31 & 2.97 & .912 & 4 \\
Item 2 & 31 & 2.61 & .803 & 3 \\
Item 3 & 31 & 3.52 & .626 & 2 \\
Item 4 & 31 & 2.97 & 1.08 & 3 \\
Item 5 & 31 & 2.81 & .910 & 3 \\
Item 6 & 31 & 2.97 & .706 & 3 \\
\hline Mean & & 2.98 & .840 & \\
\hline
\end{tabular}

The results in Table 1 indicate an overall tendency $(0=$ not relevant; 4 = relevant $)$ that the dialog concept was accepted. On the other hand, there is no extreme positive feedback from the subjects. The lack of multimodality and the sparse functional range of the cooperative system could be seen as the main reasons.

\section{Situational awareness}

The participants of all groups were asked seven questions regarding their situational awareness (SA) after each block of driving (Bolstad, 2001; Endsley \& Kaber, 1999).

Figure 2 shows the results of block 1. Over time, the SA becomes more and more similar between the groups and in block 4, the SA of the four groups is nearly the same. The difference between the cooperative system and the others is significant $(\alpha=0,05)$, but not between the other three systems. 


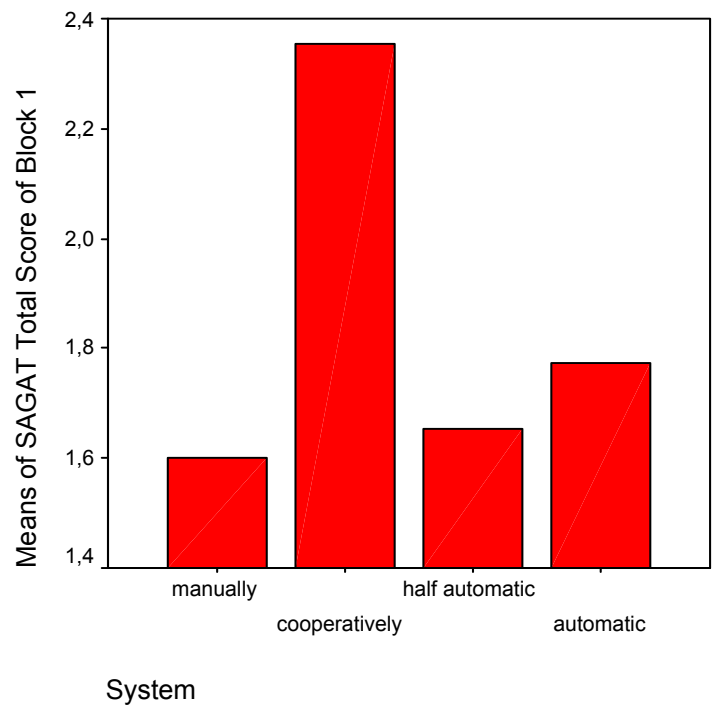

Figure 2. Means of SAGAT

\section{Trust}

Trust was measured, beside other items, with the question "Do you consider the system you were interacting with as trustworthy?" Figure 3 shows the results of this question in relation to the experienced system.

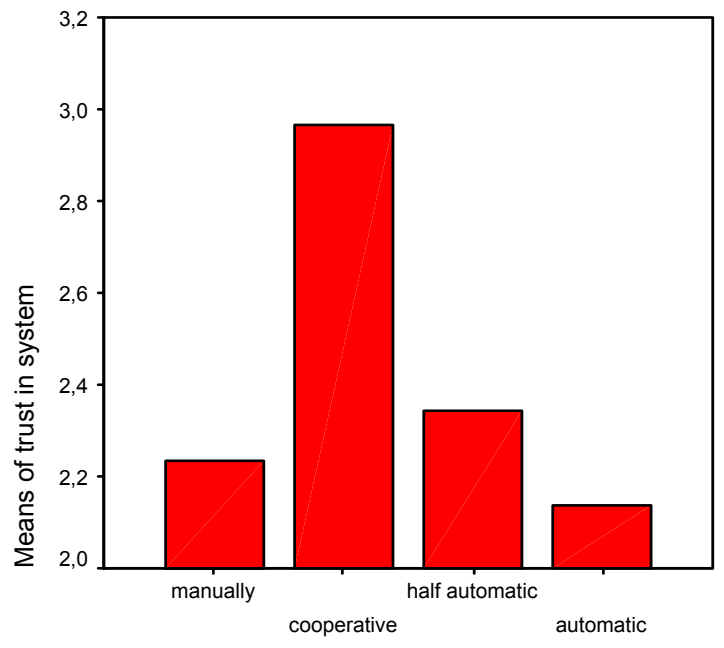

System

\section{Figure 3. Means of the answers on trust in the experienced system}

There was a significant mean difference between the cooperative and the other three systems $F(1,4)=7.65, \mathrm{p}>.05$. This shows that an interaction similar to human-human cooperation, where one system was invented as the counterpart, helped to increase trust. 


\section{DISCUSSION}

The results of the presented experiment indicate that a cooperative layout of the human-car interaction can be seen as a chance for R\&D-Departments, as the research on cooperation is a new and not yet well established field, because it helps to overcome some of the recent problems that have emerged from the present views of function- and task-allocation approaches. This refers mainly to inadequate system feedback, as well as self-initiated system behaviour and the perceived complexity of the overall system (Billings, 1997).

The concept presented here, above all, purports a high integration ability for most of the innovative systems in cars of the future.

Accompanying the theoretical discussion on the design of the future interaction, differentiated research has to be done. Especially not only in relation with the proposed concept, data must be collected that indicates if and under which circumstances drivers are motivated to interact with their cars. Only in this manner can it be decided which conceptual approach is able to provide the design solution to the problems of human-car interaction.

\section{REFERENCES}

Biester, L. (2004). Application of cooperation between human and machine in cars. Paper presented at the 21. VDI/VW-Gemeinschaftstagung, Wolfsburg.

Billings, C. E. (1997). Aviation automation: the search for a human-centered approach. Mahwah, N.J.: Lawrence Erlbaum Associates (TIB: T 97 B 5977).

Bolstad, C. A. (2001). Situation awareness: does it change with age?

Endsley, M. R., \& Kaber, D. B. (1999). Level of automation effects on performance, situation awareness and workload in a dynamic control task. Ergonomics, 42: 462-492.

Grice, H. P. (1975). Logic and conversation. In: P. Cole \& J. L. Morgan (Eds.), Syntax and Semantics: Speech acts (Vol. 3, pp. 41-58). New York: Academic Press.

Herczeg, M. (2002). Intention-Based Supervisory Control: Kooperative Mensch-Maschine Kommunikation in der Prozessführung. In: M. Grandt \& K.-P. Gärnter (Eds.), Situation Awareness in der Fahrzeug- und Prozessführung (Vol. DGLR-Bericht 2002-4, pp. 29-42). Bonn: Deutsche Gesellschaft für Luft- und Raumfahrt.

Kennedy, R. S., \& Lane, N. E. (1993). Simulator sickness questionnaire: An enhanced method for quantifying simulator sickness. International Journal of Aviation Psychology, 3(3): 203220.

Panou, M., Bekiaris, E., \& Palma, F. (2003). A new assessing system for elderly drivers and the use of ADAS/IVICS as driving support for them. Paper presented at the ITS 2003, Madrid.

Sheridan, T. B. (1992). Telerobotics, automation, and human supervisory control. Cambridge, MA: MIT Press.

Skjerve, A. B. M., \& Skraaning, G. (2004). The quality of human-automation cooperation in human-system interface for nuclear power plants. International Journal of Human Computer Studies, 61(5): 649-677. 